\title{
Temperature Control in The R-101 Reactor with Comparing the Ziegler Nichols and Tyreus - Luyben Tuning Methods
}

\author{
Utami $E^{1, *}$ A Sahrin ${ }^{1}$ N Maulidya ${ }^{1}$ \\ ${ }^{1}$ Refinery Instrumentation Engineering of Department, Politeknik Energi dan Mineral, 58315, Indonesia \\ *Corresponding author.Email: erna.alern@gmail.com
}

\begin{abstract}
The R-101 reactor is one of the units in the Catalytic Condensation Unit (CCU), XXX Refinery. This reactor functions to reprocess the mixed $\mathrm{C} 4$ feed originating from the RCC Complex processing to have a higher selling value such as propylene and LPG. In this reactor, there is a polymerization reaction between the feed and the catalyst and exothermic heat transfer so that a series of control instrumentation is needed to maintain the temperature of the incoming feed at the reactor inlet. Temperature is a factor influencing conversion. The temperature control system in reactor R-101 is a series of cascade controls by temperature outlet heater E-102 with flow steam flowing in heater E-102. This control system will be more effective if the system response is stable, namely the shorter ascent and steady-state parameters, as well as the small overshoot value. One way to do this is by tuning the PID parameters of the controller. After tuning the PID parameters for temperature control in the Reactor R 101A, it can be seen that the response graph with the Ziegler Nichols method has the most stable response compared to the actual process response and the Tyreus - Luyben tuning method but still has the same delay time parameter of 90 seconds, the long incline and steady-state is 500 seconds, but the smallest overshoot is only $0.9 \%$.
\end{abstract}

Keywords: Cascade Control, Ziegler Nichols m\#ethod, Tyreus - Luyben Method, Reactor Process.

\section{INTRODUCTION}

PT. XYZ has a Residual Catalytic Complex (RCC) unit which processes low fraction oil into high - value products such as Gasoline, Light Cycle Oil (LCO), Decant Oil, LPG, Propylene, and Polygasoline. Besides, there is a support unit to carry out advanced processing from the RCC called the Light Ends Unit (LEU) because RCC products still contain hydrocarbons consisting of Butane and lighter (Light Ends). Initially, Light Ends was not an important product because it was only used as refinery fuel. However, with LEU, Light Ends can be processed to produce products with high selling value, such as propylene and LPG. One of the units in the LEU is the Catalytic Condensation Unit (CCU). This unit is designed to process Unsaturated Mixed's Butane from RCC Complex units and produce high molecular weight products using Solid Phosphoric Acid (SPA) catalysts with a polymerization process [1][2][5].

One of the things that need to be considered in operating the $\mathrm{CCU}$ to achieve optimum conditions for producing high octane gasoline is to maintain the life of the catalyst. The reactor temperature is the main process variable used to adjust the olefin conversion rate because it is related to the activity of the catalyst. The operating temperature for SPA catalysts is between $150-225^{\circ} \mathrm{C}$. If below $150{ }^{\circ} \mathrm{C}$ causes the catalyst to soften and the reactor pressure drop will increase, if it is above $225^{\circ} \mathrm{C}$ there will be an overreaction of the olefin so that it forms Tar and causes "Coke" on the catalyst [1][3][4].

Understanding the importance of temperature control in the 20-R-101 $\mathrm{A} / \mathrm{B} / \mathrm{C}$ reactor in the Catalytic Condensation Unit underlies the researchers to compare the tuning methods of temperature control PID parameters. The introduction is an opportunity for the author to convince the reader (including editors and reviewers) that the author mastering the research carried out has significance or contributes to the field of study. 


\section{METHOD}

\subsection{Catalytic Condensation Unit}

The process in this unit is divided into four sections, namely the feed, reactor, rectification, and stabilizer sections. Figure 1 shows a process flow diagram of the 20 Catalytic Condensation Unit. The mixed C4 feed originating from the PRU unit (Unit 19) enters the Water Wash Column (20-C-101), in the bottom column through the distributor under tray no. 20. This flow will be circulated in the opposite direction to the circulating water flow. This circulation system is injected with Phosphate Acid from the Phosphate mix tank 19-V-109 in unit 19. Water from this column is used to control the $\mathrm{pH}$ of the solution, while phosphate injection is to remove the basic nitrogen components so that it does not react with the catalyst [4][6].

The mixed $\mathrm{C} 4$ then flows through the top of the column to the Feed Surge Drum 20-V-101. Inside 20-V101 the mixed $\mathrm{C} 4$ will be separated from the phosphate acid solution which is carried along with water through the bootleg and flowed to the 19-V-106 Water Degassing Drum in unit 19. Meanwhile, the clean mixed C4 will be pumped to the reactor through the feed pump 20- P-101.

Mixed C4 from 20-V-101 together with the flow from Flash Rectifier Receiver (20-V-102) to before and after combined feed exchanger 20-E-101 (as reactor effluent heater). The mixture is then injected with water from a water injection tank $20-\mathrm{V}-105$ before heating in a combined feed heater 20-E-102 (as an HP steam heater).

Then the combined feed is feed to 3 reactors of 20-R$101 \mathrm{~A} / \mathrm{B} / \mathrm{C}$ in parallel and operated simultaneously. Between the catalyst beds, a recycle quench is injected.

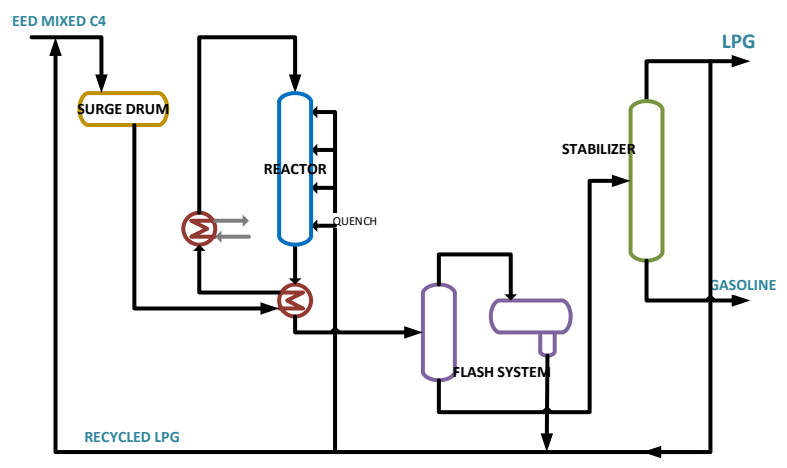

Figure 1 Process flow diagram on a CCU unit

\subsection{Temperature Control System 20-R-101}

The 20-TE-008 thermocouple sensor will read the current reactor inlet temperature and immediately send the PV value to 20-TRC-008 as a temperature recorder and controller of $0-200{ }^{\circ} \mathrm{C}$ and processed directly on the DCS. As the master controller, the 15-TRC-008 functions to calculate the error value and sends a manipulated variable data signal to the slave controller, namely the 20FRC-009 flow controller. The MV signal is received by the flow controller 20-FRC-009 as a setpoint. This controller also gets a PV signal, 4-20 mA, which is sent by the 20-FT-009 transmitter with the flow sensor used as the orifice. This controller then sends a signal of 0.4-2 $\mathrm{kg} / \mathrm{cm}^{2}$ to $20-\mathrm{FV}-009$ according to the magnitude of the error. The 20-FV-504 valve is of the FC/ATO type, so if the signal sent to the valve is $0.4 \mathrm{~kg} / \mathrm{cm}^{2}$ then the valve will be fully closed, whereas if the signal sent to the valve is $2.0 \mathrm{~kg} / \mathrm{cm}^{2}$ then the valve will be fully open.

When TE-008 detects a high temperature, this indicates that the flow of steam flowing is also higher so that it can be seen that the gain process is direct. By the TRC-008 controller action, which is reverse, PV (reactor inlet temperature) which exceeds the set point will cause the controller to issue a negative error signal (e = SP-PV). This signal is received by the FC-009 controller as a slave to its reference value (setpoint). Because the FC-009 gets a high PV (flow steam) input with the Reverse controller action, the input from the FT-009 is high, so the signal output will be lower than the MV in normal operation. This correction signal from FC-009 will be the command for the control valve. Control Valve FV-009 has a reverse or Air to Open actuator action. By receiving a signal that is lower than normal operation (negative), the actuator will reduce the water supply pressure which processes the diaphragm to decrease and causes the valve opening to decrease, the steam flow will also decrease, then the temperature will decrease and be corrected according to the desired set point.

\subsection{Transfer Function of Each Component}

\subsubsection{Thermocouple 20-TE-008}

Because the output and input have the same range, namely the temperature in Celsius $\left({ }^{\circ} \mathrm{C}\right)$, it is assumed that the temperature gain of this element is 1 , obtained from the following equation: [7]

$G_{T}(s)=\frac{\text { Output }}{\text { Input }}=1$

\subsubsection{Temperature Recorder Controller 20- TRC-008}

Based on the results of DCS data collection on February 22, 2019, the value of $\mathrm{P}=200$ (PB value), I = 50 (Ti value), D = 50 (Td value) was obtained. From this data, the transfer function can be written as follows:[7]

$$
G_{T C}=K p\left(1+\frac{1}{T i s}+T d s\right)
$$




$$
G_{T C}=\frac{1250 s^{2}+25 s+0.5}{50 s}
$$

\subsubsection{Flow Transmitter 20-FT-009}

Because the output and input of this transmitter have a range in units (\%), it is assumed that the gain of this Flow Transmitter is 1, obtained from the following equation [7].

$$
G_{T}(s)=\frac{\text { Output }}{\text { Input }}
$$

\subsubsection{Flow Controller 20-FC-009}

Based on the results of DCS data collection on February 22, 2019, it was found that the value of $\mathrm{P}=100$ ( $\mathrm{PB}$ value), $\mathrm{I}=50$ (Ti value), $\mathrm{D}=0$ (Td value). From this data, the transfer function can be written as follows:

$$
\begin{aligned}
& G_{F C}=K p\left(1+\frac{1}{T i s}+T d s\right) \\
& G_{T C}=\frac{50 s+4}{50 s}
\end{aligned}
$$

\section{RESULT AND DISCUSSION}

\subsection{Process Temperature Outlet Heater}

The transfer function in temperature changes as a disturbance can be seen from sampling through the bump test method conducted at the DCS Central Control Room on March 6, 2019. By changing the MV value by 5\%, PV shows a change from $144.15{ }^{\circ} \mathrm{C}$ to $155.66{ }^{\circ} \mathrm{C}$ shown in Figure 2. From the graph, the process transfer function parameters are obtained as follows:

Time Delay (L): The process begins to respond to the MV change response from $2: 44: 29$ to $2: 45: 33$ so that $\mathrm{L}=65$ seconds,

Time Constant (T): The PV response reaches a $63 \%$ steady - state with a change of around $10{ }^{\circ} \mathrm{C}$ at the PV value $151.3^{\circ} \mathrm{C}$

$$
(63 \% \times 10)+144,15=151,3
$$

On graph figure 2 of the time needed from PV 144.15 ${ }^{\circ} \mathrm{C}$ to $151.3^{\circ} \mathrm{C}$ for $\mathrm{T}=92$ seconds

Static Gain (K): Obtained from the comparison of changes in $\mathrm{PV}$ and comparison of changes $\mathrm{MV}$ in percent (\%) with a PV span of $150{ }^{\circ} \mathrm{C}$

$$
\Delta P V=10^{\circ} \mathrm{C}=\frac{10}{150} \times 100 \%=6,667 \%
$$

$$
K=\frac{\Delta P V}{\Delta M V}=\frac{6,667 \%}{5 \%}=1,334
$$

The transfer function of this controller is:

$$
G p=\frac{K}{T s+1} e^{-L s}=\frac{1,334}{92 s+1} e^{-65 s}
$$

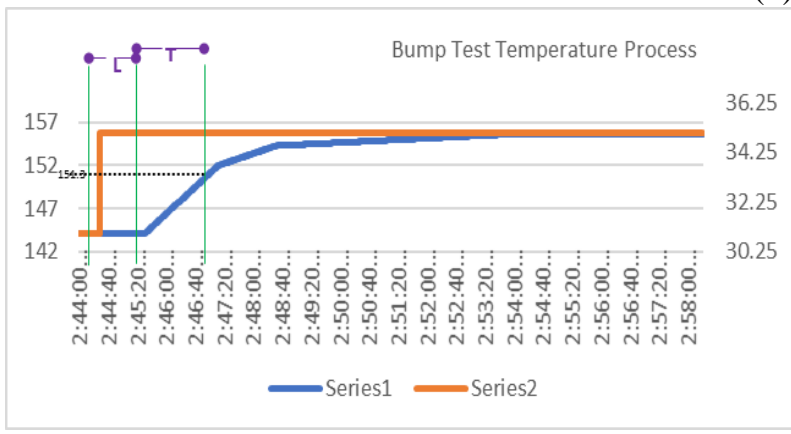

Figure 2 Process flow diagram on a CCU unit

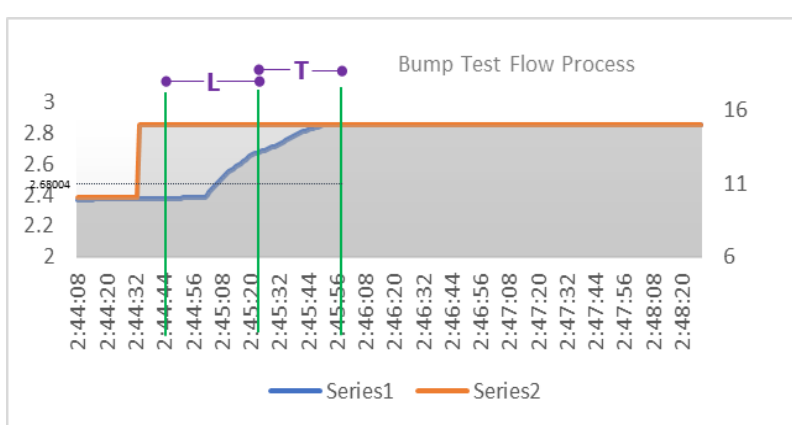

Figure 3 Bump Test Flow process on Steam 20-E-102

\subsection{Process Steam Flow}

The transfer function in temperature changes as a disturbance can be seen from sampling through the bump test method conducted at the DCS Central Control Room on March 12, 2019. By changing the MV value by 5\%, $\mathrm{PV}$ shows a change from $2,383 \mathrm{~T} / \mathrm{H}$ to $2,854 \mathrm{~T} / \mathrm{H}$ shown in the graph of figure 3 .

From the graph in Figure 3, the process transfer function parameters are obtained as follows:

Time Delay (L): The process begins to respond to the MV change response from $2: 44: 34$ to $2: 45: 01$ so that $\mathrm{L}=27$ seconds

Time Constant (T): The PV response reaches $63 \%$ at a steady - state with a change of around $0.471 \mathrm{~T} / \mathrm{H}$ at the $\mathrm{PV}$ value of $2.68 \mathrm{~T} / \mathrm{H}$

$(63 \% \times 0,471)+2,383=2,68 \mathrm{~T} / H$

In Figure 3, the graph of the time required is from PV 2.383 to 2.68 for $\mathrm{T}=25$ seconds 
Static Gain (K) is obtained from the comparison of changes in PV and comparison of changes MV is in the percent range (\%) with a PV span of $6.5 \mathrm{~T} / \mathrm{H}$

$\Delta P V=0,471 \frac{T}{H}=\frac{0,471}{6,5} \times 100 \%=7,425 \%$

$$
K=\frac{\Delta P V}{\Delta M V}=\frac{7,425 \%}{5 \%}=1,449
$$

The transfer function of this controller is:

$$
G p=\frac{K}{T s+1} e^{-s L}=\frac{1.449}{24 s+1} e^{-27 s}
$$

\subsection{Transient response of system along with $P I D$ parameter tuning with simulation in MATLAB}

To see the operational conditions in the field or the actual conditions of the 101st reactor temperature control cascade, the Simulink Matlab program is used according to the data obtained in the field. In this case, the transient response will also be observed. Transient response analysis can be done by observing the response of the system which is inputted with the step function (unit step). Based on the form of the response, the parameters of incline time, overshoot, and determination time can be found. Figure 4 shows the temperature control block diagram in reactor $20-\mathrm{R}-101 \mathrm{~A}$ and its transfer function.

By looking at the response graph of temperature control in Figure 5, it can be concluded that the control is not stable, seen from the graph that still has ripple (ripples), with a delay time of 90 seconds, 200 seconds of rise time, maximum overshoot of $0.43(43 \%)$ at 302 seconds, and the setting time is 1.453 seconds.

Tuning is done on the cascade control loop, which is tuning the inner loop in this case the flow controller 20FC-009. The block diagram along with the transfer function in this loop can be seen in Figure 6. Two tuning methods were performed on this loop, namely by ZieglerNichols and Tyreus-Luyben. Previously, the Ultimate Gain and Ultimate Period analysis had to be done by removing the Integral and Derivative algorithms (Ti and
Td became 0) and looking for the Kp value until the response became an oscillation. So that is shown in Figure 7. Ultimate Gain (Ku) was obtained at 1.4595 with an Ultimate period of 81.087 seconds. Entered in table 1 as the PID parameter.

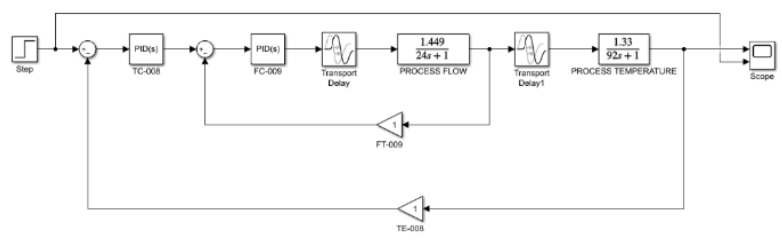

Figure 4 Temperature Cascade Control Block Diagram in actual conditions

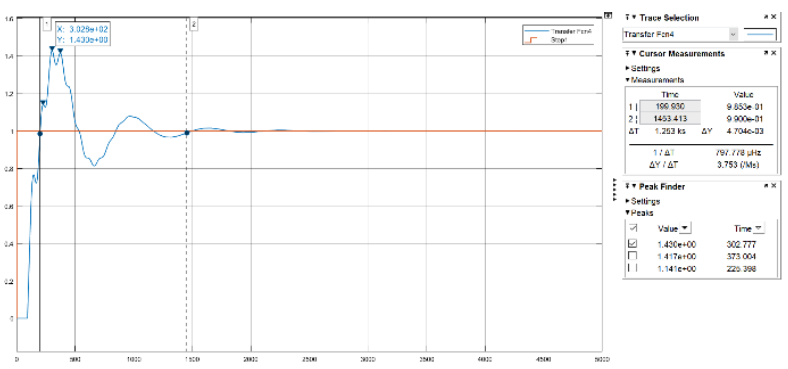

Figure 5 Temperature Response Graph Cascade Control in Actual Conditions

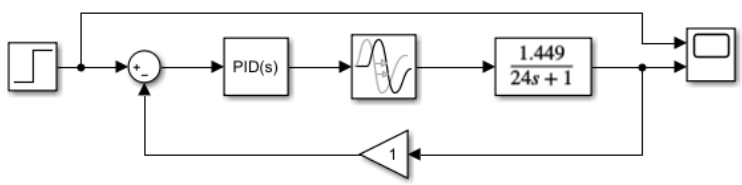

Figure 6 Secondary Block Loop Diagrams (flow)

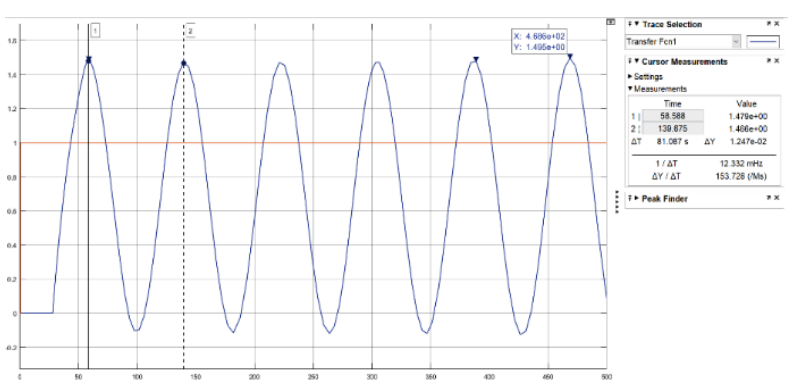

Figure 7 Secondary Loop Response Graph when $\mathrm{Kp}=$ $1.4595 \mathrm{Ti}=0 \mathrm{Td}=0$

\begin{tabular}{|c|c|c|c|c|c|}
\hline \multicolumn{3}{|c|}{ ACTUAL } & Rise time $(\mathrm{s})$ & Settling time (s) & Overshoot $(\%)$ \\
\hline $\mathrm{P}$ & \multicolumn{2}{|c|}{100} & \multirow{2}{*}{47} & \multirow{2}{*}{555} & \multirow{2}{*}{$51 \%$} \\
\hline $\mathrm{I}$ & \multicolumn{2}{|l|}{50} & & & \\
\hline \multicolumn{6}{|c|}{ ZIEGLER NICHOLS } \\
\hline $\mathrm{P}$ & $0.45 \mathrm{Ku}$ & 0.6568 & \multirow{2}{*}{61} & \multirow{2}{*}{262} & \multirow{2}{*}{$12 \%$} \\
\hline $\mathrm{I}$ & $\mathrm{Pu} / 1.2$ & 67.565 & & & \\
\hline \multicolumn{6}{|c|}{ TYREUS-LUYBEN } \\
\hline $\mathrm{P}$ & $0.31 * \mathrm{Ku}$ & 0.4524 & 61 & 406 & $47 \%$ \\
\hline
\end{tabular}

Table 1. Comparison of PID Parameters and System Response after Tuning 


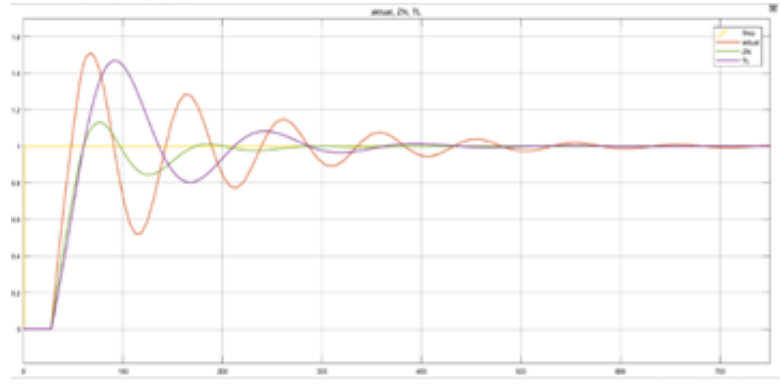

Figure 8 Comparison of Secondary Loop Response Graph (flow) after PID tuning

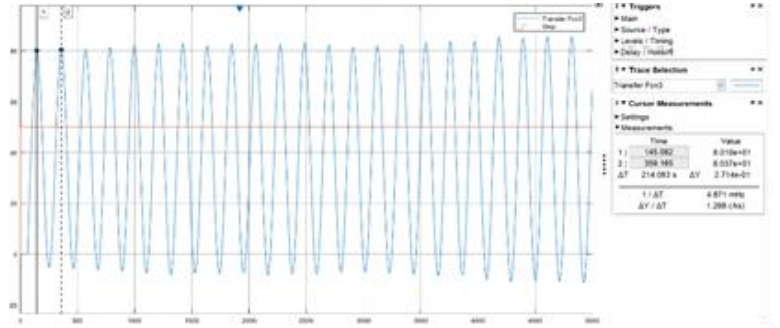

Figure 9 Primary Loop Response Graph when $\mathrm{Kp}=$ $2.2095 \mathrm{Ti}=0 \mathrm{Td}=0$

Table 2. Comparison of PID Parameters and System Response after Tuning

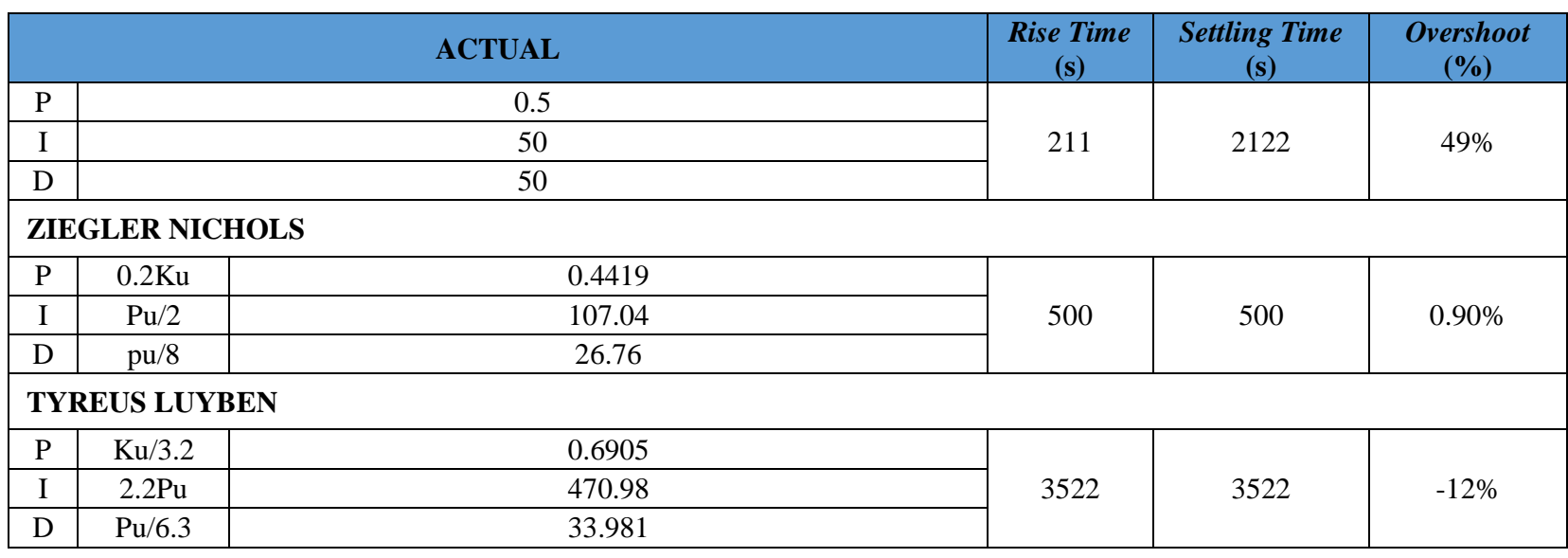

The PID parameter was chosen using the ZieglerNichols method because it has the lowest overshoot and the fastest settling time. Figure 8, Update the PID parameters in the loop cascade simulation then tuning the PID parameters on the 20-TRC-008 Temperature recorder controller using the same closed loop tuning method to find the ultimate gain $(\mathrm{Ku})$ and ultimate period $\mathrm{Pu}$ ) values.

The ultimate gain value is 2.2095 and the ultimate period is 214.083 seconds. Enter the values for $\mathrm{Ku}$ and $\mathrm{Pu}$ in table 2.

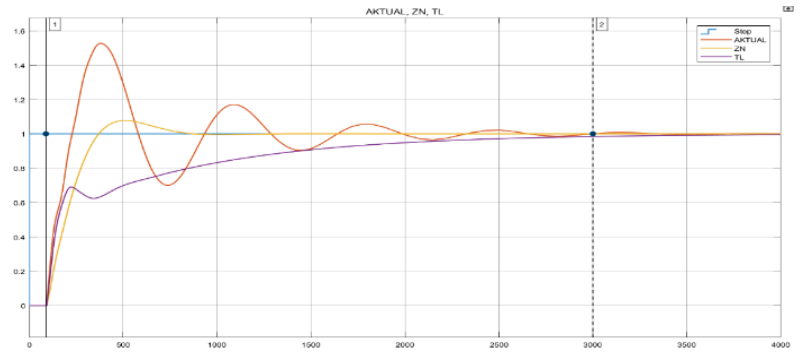

Figure 10 Comparison of Cascade Control Temperature Response Graph after PID tuning

In Figure 10, it can be seen that after tuning with the Ziegler-Nichols method, the transient response appears to have an overshoot that is smaller than the actual response of $0.9 \%$ and a faster settling time of 500 seconds. However, the rise time is longer than the actual response, which is 500 seconds. While tuning with the Tyreus-Leuben method, it can be seen that the response has overdamped by $12 \%$ which causes the longest rise and settling time compared to the Ziegler-Nichols method and the actual system, which is 3522 seconds.

\section{CONCLUSION}

Configuration of Temperature Control System on reactor 20-R-101 in the form of cascade control with Temperature Controller as master control and Flow Controller as slave control. If a high temperature can indicate high steam flow, the flow control valve will close to reduce steam flow in the heater and reduce the temperature of the reactor inlet, vice versa. In the actual system response, it is known that the response graph is still not smooth, has a delay time of 90 seconds, a rise time of 200 seconds, a maximum overshoot of 0.43 $(43 \%)$ at 302 seconds, and a settling time. time) of 1.453 seconds. After tuning the PID parameters in Figure 4.16, it can be seen that the response graph with the Ziegler Nichols method has the most stable response compared to the actual process response and the Tyreus-Luyben tuning method but still has the same delay time parameters, namely 90 seconds, the incline time and the steady time are is longer by 500 seconds, but the smallest overshoot is only $0.9 \%$. 


\section{ACKNOWLEDGMENT}

The author would like to thank the Politeknik Energi dan Mineral Akamigas Cepu, the Ministry of Energy and Mineral Resources who has provided support to the author, in particular the Research and Community Development Unit (UPPM) of the Politeknik Energi dan Mineral Akamigas Cepu.

\section{REFERENCES}

[1] Robert L. Mehlberg, Peter R. Pujado', and Dennis J. Ward. Olefin Condensation. USA, Springer International Publishing Switzerland, DOI 10.1007/978-3-319-14529-7_6, 2015

[2] Aaron Akah, Musaed Al-Ghrami. 2015. Maximizing propylene production via FCC technology. Appl Petrochem Res, 5:377-392, DOI 10.1007/s13203-015-0104-3, 2015

[3] M.F. Mohamed a , W.M. Shehata b, A.A. Abdel Halim c , F.K. Gad. Improving gasoline quality produced from MIDOR light naphtha isomerization unit. Egyptian Journal of Petroleum, Volume 26, Issue 1, March 2017, Pages 111-124. https://doi.org/10.1016/j.ejpe.2016.02.009, 2016
[4] Ronghou Liua, Manobendro Sarker, Md. Maksudur Rahmana, Chong Li, Meiyun Chai, Nishua, Raphaëlle Cotillona, Norman R. Scott. Multi-scale complexities of solid acid catalysts in the catalytic fast pyrolysis of biomass for bio-oil production - A review. Elseveir Progress in Energy and Combustion Science, Volume 80, September 2020, 100852.

https://doi.org/10.1016/j.pecs.2020.100852, 2020.

[5] Barbara Hazard Browning. Dynamic Modelling of a Fixed Bed Reactor to Study the First Instants of Gas Phase Ethylene Polymerisation. Chemical and Process Engineering. Université Claude Bernard Lyon I. English. ffNNT : 2013LYO10109ff. fftel01175971, 2013.

[6] Mina Alyani, Jafar Towfighi , and Seyed Mojtaba Sadrameli. Effect of process variables on product yield distribution in thermal catalytic cracking of naphtha to light olefins over Fe/HZSM-5. Korean J. Chem. Eng., 28(6), 1351-1358. DOI: 10.1007/s11814-010-0518-7. 2011.

[7] Utami E, Alfin Sahrin, Utomo G.R, Purnomo M. H. Cascade Control With PID - PSO Method on The Stabilizer Unit. PROCEEDING The 2nd International Conference on Applied Electromagnetic Technology (AEMT), 2019. 